\title{
CORPORATE GOVERNANCE DAN KINERJA KEUANGAN SERTA NILAI PERUSAHAAN PADA PERUSAHAAN DI INDONESIA
}

\author{
Oleh: Rina Tjandrakirana ${ }^{1}$, Ubaidillah, Dwirini \\ (UNIVERSITAS SRIWIJAYA PALEMBANG) \\ ${ }^{1)}$ p3m_iwan@yahoo.com
}

\begin{abstract}
Abstrak
Penelitian ini membuktikan secara empiris pengaruh Corporate Governance terhadap kinerja keuangan dan nilai perusahaan pada perusahaan di Indonesia. Metode pengambilan sampel yang digunakan adalah dokumentasi dan diperoleh sampel sebanyak 67 pengamatan pada perusahaan di Indonesia. Penelitian ini dilakukan pada tahun 2014 s/d 2016 dan menggunakan data primer dan sekunder. Proses analisis data yang dilakukan adalah teknik statistik deskriptif, dilanjut uji data panel kemudian memperkirakan model menggunakan model efek umum, model efek tetap dan model efek acak. Pengujian dalam penelitian ini menggunakan software SPSS versi 16. Berdasarkan hasil penelitian diketahui bahwa hasil yang positif dan signifikan antara Corporate Governance dan ROA (Model 1), ROE (Model 2). Hal senada juga menunjukkan nilai yang positif signifikan antara Corporate Governance dan nilai perusahaan.
\end{abstract}

Kata Kunci : Corporate Governance, Kinerja Keuangan, dan Nilai Perusahaan.

\section{CORPORATE GOVERNANCE AND FINANCIAL PERFORMANCE AND COMPANY VALUES IN COMPANIES IN INDONESIA}

\begin{abstract}
This study empirically proves the influence of Corporate Governance on financial performance and corporate value in companies in Indonesia. The sampling method used is documentation and obtained a sample of 67 observations in companies in Indonesia. This research was conducted in 2014 until 2016 and used primary and secondary data. The data analysis process was carried out using descriptive statistical techniques, followed by panel data testing and then estimating the model using a general effect model, fixed effects model and random effects model. The test in this study uses SPSS version 16 software. Based on the results of the study it is known that the positive and significant results between Corporate Governance and ROA (Model 1), ROE (Model 2). The same thing also shows a significant positive value between Corporate Governance and corporate value.
\end{abstract}

Keywords: Corporate Governance, Financial Performance, and Corporate Value 
PENDAHULUAN

Perhatian dan penelitian publik terhadap Corporate Governance (CG) telah semakin penting dalam beberapa tahun terakhir di berbagai negara. CG telah menjadi topik penelitian akademis yang terkenal, dan mekanisme Corporate Governance bervariasi di seluruh dunia (Mutairi et al., 2012). GCG membantu pembangunan ekonomi berkelanjutan dengan meningkatkan kinerja perusahaan (GRI, 2006). Beberapa studi penelitian (Dittmar et al., 2003; Nam dan Nam, 2004; Rashid dan Islam, 2013) menunjukkan bahwa Corporate Governance memiliki peran penting dalam mempengaruhi kinerja perusahaan di pasar keuangan. Selain itu, tujuan utama mendirikan perusahaan adalah untuk meningkatkan kesejahteraan pemilik perusahaan atau pemangku kepentingan atau memaksimalkan properti pemangku kepentingan dengan meningkatkan nilai perusahaan (Brigham dan Houston, 2006). Di samping itu, tujuan sebuah perusahaan juga untuk mengoptimalkan nilai stakeholder yang dapat dicapai melalui penerapan fungsi manajemen keuangan (Wahyudin, 2012). Keputusan keuangan dapat mempengaruhi keputusan keuangan lainnya dan menyebabkan kenaikan nilai perusahaan. Kerangka kerja Corporate Governance merekomendasikan pemaksimalan nilai pemangku kepentingan adalah hasil mekanisme Corporate Governance (Mutairi et al., 2012).

Corporate Governance prihatin dengan hubungan para manajer, dewan direksi, karyawan, pengontrol, minoritas dan pemangku kepentingan lainnya. Abor (2007) menjelaskan bahwa Corporate Governance mengacu pada bagaimana perusahaan seharusnya dijalankan, diatur dan dikendalikan. Menurut Kaihatu (2006), esensi Corporate Governance meningkatkan kinerja perusahaan dengan mengawasi atau memantau kinerja manajemen dan akuntabilitas pemangku kepentingan lainnya, berdasarkan kerangka peraturan dan peraturan yang berlaku. Corporate Governance dapat menghasilkan goodwill dan kepercayaan investor. Temuan Gompers dkk. (2003) menjelaskan bahwa GCG dapat memperbaiki penilaian dan dukungan dari investor.

Berbagai tanggapan yang dihasilkan dari isu Corporate Governance muncul dari banyak negara. Di Indonesia, akademisi tertarik 
untuk mempelajari isu CG. Selanjutnya, para akademisi dan praktisi juga membentuk berbagai forum, seperti Forum Corporate Governance di Indonesia (FCGI), Indonesian Institute for Corporate Governance (IICG) dan Pusat Tata Kelola Perusahaan yang Baik di Fakultas Ekonomika dan Bisnis Universitas Gadjah Mada. FCGI bekerja sama dengan Asian Development Bank (ADB) telah mengembangkan sebuah penilaian sendiri sebagai instrumen untuk menilai implementasi CG perusahaan di Indonesia. Di sisi lain, IICG bekerja sama dengan Komite Nasional untuk corporate governance (NCG) melakukan studi penelitian dan penilaian pelaksanaan CG di perusahaan publik dan swasta, bank dan perusahaan milik negara di Indonesia. Hasilnya kemudian dipublikasikan secara nasional dan internasional oleh Majalah SWA dan situs IICG.

Sebuah penelitian yang dilakukan oleh Indonesian Institute for Corporate Governance (IICG) pada tahun 2002 menemukan bahwa alasan utama perusahaan untuk menerapkan CG adalah kepatuhan terhadap peraturan. Corporate Governance Perception Index (CGPI) tidak hanya mempertimbangkan kualitas Corporate
Governance tetapi juga mengundang perusahaan untuk meningkatkan komitmen dan kualitas pemerintahan melalui diseminasi, benchmarking, evaluasi dan gradasi dan perbaikan terus-menerus. Perusahaan percaya bahwa implementasi CG adalah bentuk penegakan etika bisnis dan pekerjaan lainnya yang telah menjadi komitmen perusahaan, dan terkait dengan peningkatan citra perusahaan. Perusahaan yang menerapkan Corporate Governance dapat memperbaiki citra dan nilai perusahaan mereka. Implementasi Corporate Governance di Indonesia diukur dengan IICG. Indonesian Institute for Corporate Governance (IICG) telah mengukur pelaksanaan CG di Indonesia sejak tahun 2001. Oleh karena itu, penelitian ini bertujuan untuk mengeksplorasi pengaruh penilaian CGPI terhadap kinerja berbasis akuntansi yaitu kinerja keuangan dan nilai perusahaan. Masalah yang diangkat dalam penelitian ini adalah sebagai berikut:

1. Bagaimana pengaruh Corporate Governance terhadap kinerja keuangan? 
2. Bagaimana pengaruh Corporate Governance terhadap nilai perusahaan?

\section{METODE PENELITIAN}

\section{Desain Penelitian}

Studi ini menganalisis perusahaan yang terdaftar yang berpartisipasi dalam CGPI Awards. Baru-baru ini, peringkat $\mathrm{CG}$ di Indonesia bersifat sukarela; Karena itu, hanya sejumlah kecil masyarakat Perusahaan berpartisipasi. Sampel penelitian ini terdiri dari 37 perusahaan yang tercatat di Bursa Efek Indonesia (BEI) dan khususnya berpartisipasi dalam CGPI Awards.

\section{Data Dan Sumber Data}

Data terdiri data primer dan data sekunder. Data primer adalah data yang langsung diperoleh dari narasumber (data asli) dengan cara observasi dan wawancara. Sedangkan, data sekunder yang digunakan dalam penelitian ini adalah data laporan tahunan yang diperoleh dari website resmi Bursa Efek Indonesia dan atau website resmi masing-masing perusahaan.

\section{Metode Pengumpulan Data}

Metode pengumpulan data yang dilakukan dalam penelitian ini menggunakan dokumentasi, dengan cara mengumpulkan data sekunder dari berbagai sumber, baik secara pribadi maupun kelembagaan dan observasi yang dilakukan pada saat melakukan content analysis terhadap Corporate Governance, Kinerja keuangan dan nilai perusahaan

\section{Definisi Variabel Operasional Variabel bebas}

Variabel independen dari penelitian ini adalah penilaian penerapan $\mathrm{CG}$, sedangkan indikator yang digunakan dalam penelitian ini adalah CGPI yang diambil dari program penelitian dan penilaian yang dilakukan oleh IICG.

\section{Variabel dependen}

Variabel dependen yang digunakan dalam penelitian ini dikategorikan menjadi tiga kelompok, seperti yang dijelaskan pada Tabel 1. 
Tabel 1. Pengukuran Variabel Dependen

\begin{tabular}{|l|l|l|l|}
\hline No & Variabel & Indikator & Pengukuran \\
\hline 1 & Kinerja Keuangan & ROA (Return on Asset) & Net profif after tax / total aset \\
\cline { 3 - 4 } & & ROE (Return on Equity) & $\begin{array}{l}\text { Net profit after tax/ } \\
\text { Stakeholder's equity }\end{array}$ \\
\cline { 3 - 4 } & & EPS & $\begin{array}{l}\text { Net Profit after tas/number of } \\
\text { shares }\end{array}$ \\
\hline 2 & Nilai Pasar & PBV (Price to Book Value) & Share price/Share book value \\
\hline
\end{tabular}

\section{Variabel kontrol}

Untuk mendapatkan model penelitian dan hasil analisis yang lebih baik, penelitian ini menggunakan variabel kontrol. Setelah penelitian sebelumnya (Hassan dan Halbouni, 2013; Sheikh et al., 2013), penelitian ini juga menggunakan variabel kontrol, termasuk ukuran perusahaan, umur perusahaan, usia dan pengaruh leverage. Pengukuran masing-masing variabel kontrol disajikan pada Tabel 2.

Tabel 2. Pengukuran dari Variabel

kontrol

\begin{tabular}{|l|l|l|}
\hline No & Variabel & Pengukuran \\
\hline 1 & $\begin{array}{l}\text { Ukuran } \\
\text { perusahaan } \\
\text { (Size) }\end{array}$ & $\begin{array}{l}\text { Natural } \\
\text { logarithm of } \\
\text { Total Asset }\end{array}$ \\
\hline 2 & $\begin{array}{l}\text { Umur } \\
\text { perusahaan } \\
\text { (AGE) }\end{array}$ & $\begin{array}{l}\text { Research year- } \\
\text { company } \\
\text { establishment } \\
\text { year }\end{array}$ \\
\hline 3 & $\begin{array}{l}\text { Leverage } \\
\text { (LEV) }\end{array}$ & $\begin{array}{l}\text { Debt book } \\
\text { value/total aset }\end{array}$ \\
\hline
\end{tabular}

\section{Metode Analisis Data}

Data yang terkumpul selanjutnya diperiksa dengan menggunakan teknik statistik deskriptif termasuk mean, standar deviasi, maksimum, nilai minimum serta tabel dan grafik. Kemudian data dianalisis dengan menggunakan regresi dengan software SPSS. Pada regresi data panel, pertama, kami memperkirakan model menggunakan model efek umum, model efek tetap dan model efek acak. Dalam menyelidiki hubungan antara Corporate Governance dan kinerja, kami menerapkan lima model berikut.

Model 1 ROA $=\beta_{0}+\beta_{1}$ CGPI + $\beta_{2}$ SIZE $+\beta_{3}$ AGE $+\beta_{4}$ LEV $+e$

Model 2 ROE $=\beta_{0}+\beta_{1}$ CGPI + $\beta_{2}$ SIZE $+\beta_{3}$ AGE $+\beta_{4}$ LEV + e

Model 3 EPS $=\beta_{0}+\beta_{1}$ CGPI + $\beta_{2} \mathrm{SIZE}+\beta_{3} \mathrm{AGE}+\beta_{4} \mathrm{LEV}+\mathrm{e}$

Model 4 PBV $=\beta_{0}+\beta_{1}$ CGPI + $\beta_{2} \mathrm{SIZE}+\beta_{3} \mathrm{AGE}+\beta_{4} \mathrm{LEV}+\mathrm{e}$

\section{Pembahasan}

\section{Data Penelitian}

Penelitian ini memperoleh data dari beberapa perusahaan yang terlist dari Corporate Governance Perception 
Index (CGPI) dari tahun 2014-2016.

CGPI adalah peringkat praktik tata

kelola perusahaan di Indonesia

Perusahaan yang terdaftar di Indonesia

yang dilakukan oleh Indonesian

Institute for Corporate Governance

(IICG). Total perusahaan yang menjadi sampel adalah sebanyak 23 perusahaan.

Data dalam penelitian ini adalah sebanyak 67 pengamatan. Data terlampir dalam lampiran I.

\section{Analisis Statistik Deskriptif}

Tabel 3. Statistik Deskriptif

\begin{tabular}{cccccc}
\hline Variabel & Minimum & Median & Maximum & Mean & Std. Deviation \\
\hline CGPI & 77.27 & 85.6300 & 93.00 & 84.5287 & 4.04158 \\
SIZE & 20.13 & 23.8500 & 27.63 & 23.7381 & 1.99930 \\
LEVERAGE & 10.50 & 62.5000 & 91.93 & 59.2818 & 24.68142 \\
AGE & 8.00 & 47.0000 & 160.00 & 51.9701 & 33.94647 \\
ROA & .04 & 3.5700 & 15.60 & 4.5282 & 3.49796 \\
ROE & .11 & 13.6000 & 31.19 & 13.9999 & 7.21538 \\
EPS & 11.00 & 465.0000 & 9906.00 & 850.0448 & 1814.21022 \\
PBV & .51 & & 3.89 & 1.7007 & .95565 \\
\hline
\end{tabular}

$\mathrm{N}=67$

Sumber: Data Sekunder yang diolah

Nilai mean dari data terlihat bahwa skor berkisa diantar 84.5 yang artinya perusahaan ini berada pada level dipercaya (trusted) mengacu dari tabel 2.2. Dilihat dari kinerja keuangan yang menggunakan ROA, ROE dan EPS perusahaan-perusahaan ini memiliki kinerja yang baik.

\section{Uji Hipotesis}

Tabel 4. Hasil Pengujian Hipotesis

\begin{tabular}{|c|c|c|c|c|c|c|c|c|}
\hline Variable & \multicolumn{2}{|c|}{ Model 1} & \multicolumn{2}{|c|}{ Model 2} & \multicolumn{2}{|c|}{ Model 3} & \multicolumn{2}{|c|}{ Model 4} \\
\hline Constant & 17.549 & .062 & -8.568 & .642 & 4589.152 & .396 & 7.017 & .006 \\
\hline CGPI & -.039 & .717 & .301 & .165 & -64.360 & .309 & .011 & .696 \\
\hline SIZE & -.377 & .107 & -.483 & .294 & 49.002 & .715 & -.286 & $.000 * *$ \\
\hline LEV. & -.048 & $.005 *$ & .068 & .041 & 7.845 & .414 & .004 & .421 \\
\hline AGE & .040 & $.005 *$ & .088 & $.002 *$ & 1.402 & .860 & .006 & .096 \\
\hline Adjusted $\mathrm{R}^{2}$ & \multicolumn{2}{|c|}{0.171} & \multicolumn{2}{|c|}{0.280} & \multicolumn{2}{|c|}{0.040} & \multicolumn{2}{|c|}{0.226} \\
\hline F Statistic & \multicolumn{2}{|c|}{4.410} & \multicolumn{2}{|c|}{6.021} & \multicolumn{2}{|c|}{0.364} & \multicolumn{2}{|c|}{5.816} \\
\hline Prob & \multicolumn{2}{|c|}{$0.03 *$} & \multicolumn{2}{|c|}{$0.000 * *$} & \multicolumn{2}{|c|}{0.833} & \multicolumn{2}{|c|}{$0.000 * *$} \\
\hline
\end{tabular}

Catatan: $\mathrm{N}=67 ; *=$ Signifikan $5 \%$; ** = Signifikan 1\%

Sumber: Data Sekunder yang diolah

Dari hasil pengujian hipotesis pada Tabel 4 terlihat bahwa nilai yang positif dan signifikan adalah Corporate Governance dan ROA (Model 1), ROE
(Model 2). Model 1 signifikan pada level dibawah 5\% $(0,05)$, namun model 2 signifikan dibawah pada level $1 \%$ $(0,01)$. Hal senada juga terlihat pada 
model 4 yang menunjukkan nilai yang positif signifikan antara corporate governance dan nilai perusahaan. Hasil dapat dilihat pada Lampiran II.

Variabel kontrol yang digunakan dalam penelitian ini adalah ukuran perusahaan (Size), Leverage, umur perusahaan (Age). Penelitian ini menunjukkan hasil yang bervariasi untuk variabel kontrol untuk tiap model dalam penelitian ini. Dari Model 1 variabel kontrol yang signifikan adalah leverage dan umur perusahaan (Age) pada level 5\% (0,05). Pada Model 2 hanya umur perusahaan (Age) yang signifikan pada level 5\% $(0,05)$. Pada Model 4 yang signifikan hanya ukuran perusahaan (Size) pada level 1\% $(0,01)$. Namun pada Model 3 menunjukkan hasil yang tidak signifikan untuk semua variabel kontrol tersebut. Umur perusahaan memengaruhi kinerja keuangan (ROA dan ROE). Leverage berpengaruh terhadap ROA. Ukuran perusahaan (Size) berpengaruh terhadap nilai perusahaan (PBV).

\section{Pengaruh Corporate Governance terhadap kinerja keuangan}

Hipotesis pertama yang diajukan adalah "Sebuah perusahaan dengan implementasi $\mathrm{CG}$ yang lebih baik mungkin memiliki kinerja keuangan yang lebih tinggi”. Pengukuran kinerja keuangan dalam penelitian ini menggunakan ROA, ROE dan EPS. Hasil menunjukkan bahwa Corporate Governance dan kinerja keuangan menunjukkan hasil yang positif dan signifikan untuk ROA (Model 1) dan ROE (Model 2).

Penelitian yang dilakukan oleh Gompers dkk. (2003), dengan menggunakan indeks tata kelola yang sama, menemukan bahwa perusahaan dengan hak pemangku kepentingan yang lebih kuat cenderung memiliki keuntungan lebih tinggi. Sheikh et al. (2013) juga menemukan hubungan positif antara ukuran dewan dan kinerja perusahaan. Hasil ini kongruen dengan penelitian sebelumnya yang dilakukan oleh Jackling dan Johl (2009), Ehikioya (2009) dan Abor and Biekpe (2007). Sebuah penelitian mengenai perusahaan non-keuangan yang terdaftar di Bursa Efek Karachi Pakistan oleh Sheikh et al. (2013) membuktikan bahwa konsentrasi kepemilikan berpengaruh secara positif terhadap ROA, ROE dan EPS.

Pengukuran untuk variabel kinerja keuangan dalam penelitian ini adalah ROA, ROE dan EPS. Ini digunakan untuk mengukur 
profitabilitas berdasarkan penelitian yang dilakukan oleh Hasan dan Halbouni (2013), yang menggunakan pengukuran ROA dan ROE berbasis akuntansi pada kinerja perusahaan. Hasil kami menunjukkan bahwa peringkat CGPI memiliki dampak signifikan terhadap kinerja akuntansi (ROA, ROE dan EPS). Mekanisme CG yang diimplementasikan dengan baik tercermin dalam kinerja perusahaan (Sunarto, 2003).

$$
\text { Temuan penelitian ini }
$$
mendukung penelitian yang telah dilakukan oleh Hasan dan Halbouni (2013), yang ditemukan bahwa Corporate Governance mempengaruhi kinerja keuangan perusahaan. Dalam sebuah penelitian yang dipimpin oleh Hasan dan Halbouni (2013), Corporate Governance diukur dengan menggunakan mekanisme Corporate Governance yang terdiri dari sukarela pengungkapan, kualitas CEO dan ukuran dewan. Sementara itu, penelitian yang dilakukan oleh Sheikh et al. (2013) menggunakan pengukuran internal Corporate Governance yang lebih lengkap, termasuk ukuran papan, direktur luar, dualitas CEO, kepemilikan manajerial dan konsentrasi kepemilikan. Itu Hasil penelitian menunjukkan bahwa ukuran dewan berpengaruh positif terhadap ROA, EPS dan market-to-book (MB), sedangkan direktur luar dan kepemilikan manajerial memiliki pengaruh negatif. Temuan ini didukung dengan penelitian sebelumnya yang dilakukan di berbagai negara, seperti oleh Gompers dkk. (2003), Abor dan Biekpe (2007), Jackling dan Johl (2009), Ehikioya (2009), Reddy dkk. (2010), Siagian et al. (2013) dan Sheikh et al. (2013).

$$
\text { Temuan ini memperkuat }
$$
pernyataan Jensen dan Meckling (1976) bahwa perusahaan dengan tata kelola yang baik mungkin lebih efisien kinerja operasional Manajer bekerja secara efektif dan efisien untuk mengurangi biaya modal dan meminimalkan risiko, yang pada akhirnya dapat menghasilkan profitabilitas yang lebih tinggi.

\section{Pengaruh Corporate Governance terhadap nilai perusahaan}

Hipotesis kedua yang diajukan adalah "Perusahaan dengan implementasi Corporate Governance yang lebih baik dapat meningkatkan nilai perusahaannya di pasar saham". Nilai perusahaan dalam penelitian ini menggunakan PBV. Hasil menunjukkan bahwa Corporate 
Governance dan nilai perusahaan menunjukkan hasil yang positif dan signifikan (Model 4).

Penelitian sebelumnya yang dilakukan di Indonesia oleh Siagian et al. (2013) menemukan bahwa indeks Corporate Governance berpengaruh positif terhadap harga terhadap nilai buku (PBV) dengan menggunakan 125 sampel perusahaan di Bursa Efek Jakarta pada tahun 2003 dan 2004. Selanjutnya, hasil penelitian yang dilakukan oleh Mollah dkk. (2012) menemukan bahwa perusahaan di Botswana memiliki orientasi lanjutan dalam sistem berorientasi pasar dalam mengembangkan mekanisme Corporate Governance.

\section{Kesimpulan}

Penelitian menunjukkan hasil yang positif dan signifikan antara Corporate Governance dan ROA (Model 1), ROE (Model 2). Hal senada juga menunjukkan nilai yang positif signifikan antara Corporate Governance dan nilai perusahaan. Di Indonesia, perusahaan yang berpartisipasi dalam penilaian Corporate Governance Perception Index (CGPI) selalu mengalami peningkatan kuantitas dan kualitas setiap tahunnya. Artinya kesadaran GCG telah meningkat. Peringkat Corporate Governance perusahaan di Indonesia mempengaruhi perusahaan berbasis akuntansi kinerja, seperti ROA, dan ROE. Studi ini juga menemukan bahwa berpengaruh secara signifikan terhadap peringkat CGPI dan nilai perusahaan. Penelitian tentang peringkat CGPI yang dilakukan oleh Indonesian Institute for Corporate Governance (IICG) setiap tahunnya tidak terlalu berguna bagi investor atau calon investor dalam mengambil keputusan investasinya di pasar saham. Karena itu, IICG harus mempublikasikan rating CGPI secara luas dan mudah dapat diakses oleh publik. Pemerintah diharapkan dapat mendukung IICG untuk memperbaiki kualitas hasil penelitian dan hasilnya dipublikasikan. Misalnya, pemerintah bisa menyediakannya dana untuk IICG, karena mereka adalah organisasi nirlaba. Selain itu, bursa saham otoritas di Indonesia disarankan untuk membuat kebijakan bagi perusahaan untuk mengikuti rating Corporate Governance Program, karena hasil penelitian ini menunjukkan bahwa rating Corporate Governance dapat meningkat kinerja 
(Berthelot et al., 2010; Mishra dan Mohanty, 2014).

\section{DAFTAR PUSTAKA}

Abor, J. (2007), "Corporate governance and financing decisions of Ghananian listed firms", CorporateGovernance, Vol. 7 No. 1, pp. 83-92.

Abor, J. and Biekpe, N. (2007), "Corporate governance, ownership structure and performance of SMEsin Ghana: implications for financing opportunities", Corporate Governance, Vol. 7 No. 3, pp. 288-300.

Brigham, E.F. and Houston, J.F. (2006), Fundamentals of Financial Management, Salemba Empat,Jakarta.

Dittmar, A., Mahrt-Smith, J. and Servaes, H. (2003), "International corporate governance and corporate cash holdings", The Journal of Financial and Quantitative Analysis, Vol. 38 No. 1, pp. 111-133.

Ehikioya, B.I. (2009), "Corporate governance structure and firm performance in developingeconomies: evidence from Nigeria", Corporate Governance, Vol. 9 No. 3, pp. 231-243.

Forum for Corporate Governance in Indonesia (FCGI) (2011), "Profile FCGI", available at: www.fcgi.or.id/about-fcgi/fcgiprofile.html

Global Reporting Initiative (GRI) (2006), "Sustainability reporting guidelines 2000-2006", available at:www.globalreporting.org/resou rcelibrary/Bahasa-Indonesian (accessed 20 October 2013).
Gompers, P.A., Ishii, J.L. and Metrick, A. (2003), "Corporate governance and equity prices", QuarterlyJournal of Economics, Vol. 118 No. 1, pp. 107-155.

Hasan, A. and Butt, S.A. (2009), "Impact of ownership structure and corporate governance on capitalstructure of Pakistani listed companies". International Journal of Business and Management, Vol. 4No. 2, pp. 50-57.

Hasan, K.M. and Halbouni, S.S. (2013), "Corporate governance, economic turbulence and financialperformance of UAE listed firms", Studies in Economics and Finance, Vol. 30 No. 2, pp. 118-138.

Jackling, B. and Johl, S. (2009), "Board structure and firm performance: evidence from India's topcompanies", Corporate Governance: An International Review, Vol. 17 No. 4, pp. 492509.

Jensen, M.C. and Meckling, W.H. (1976), "Theory of the firm: managerial behavior agency cost, andownership structure", Journal of Finance Economics, Vol. 3 No. 4, pp. 305-360.

Kaihatu, T.S. (2006), "Good corporate governance and the practice in Indonesia", Journal Manajemendan Kewirausahaan, Vol. 8 No. 1, pp. 1-9.

Mollah, S., Farooque, O. and Karim, W. (2012), "Ownership structure, corporate governance and firmperformance evidence from an African emerging market", Studies in Economics and Finance, Vol. 29No. 4, pp. 301319.

Mutairi, A.M., Tian, G., Hasan, H. and Tan, A. (2012), "Corporate governance and corporate 
financepractices in a Kuwait Stock Exchange market listed firm: a survey to confront theory with practice",Corporate Governance, Vol. 12 No. 5, pp. 595-615.

Nam, S. and Nam, C. (2004), Corporate Governance in Asia: Recent Evidence from Indonesia, Republic of Korea, Malaysia, and Thailand, Asian Development Bank Institute, Manila.

Rashid, K. and Islam, S.M.N. (2013), "Corporate governance, complementarities and the value of a firmin an emerging market: the effect of market imperfections", Corporate Governance, Vol. 13 No. 1,pp. 70-87.

Reddy, K., Locke, S. and Scrimgeour, F. (2010), "The efficacy of principle-based corporategovernance practices and firm financial performance: an empirical investigation", International Journalof Managerial Finance, Vol. 6 No. 3, pp. 190-219.

Sheikh, A.N. and Wang, Z. (2012), "Effects of corporate governance on capital structure: empiricalevidence from Pakistan", Corporate Governance, Vol. 12 No. 5, pp. 629-641.

Sheikh, A.N., Wang, Z. and Khan, S. (2013), "The impact of internal attributes of corporate governanceon firm performance evidence from Pakistan", International Journal of Commerce and Management, Vol. 23 No. 1, pp. 38-55.

Siagian, F., Siregar, S.V. and Rahadian, Y. (2013), "Corporate governance, reporting quality, and firmvalue: evidence from Indonesia", Journal of Accounting in Emerging Economie, Vol. 3 No. 1, pp. 4-20.

Sunarto, S. (2003), "Corporate governance and market performance", Fokus Ekonomi, Vol. 2, No. 3, pp. 72-90.

Wahyudin, A. (2012), "The effect of ownership structure on debt policy, the principles of CorporateGovernance as an intervening variable", Thesis, Diponegoro University, Tembalang. 